auteurs

ANGELA

LANGERAK

verpleegkundig specia-

list neuromusculaire

ziekten, Amsterdam

UMC, locatie AMC

JOLIEN VAN DER

GEUGTEN

onderzoeker en

docent, masteroplei-

ding advanced nursing

practice / lectoraat

ggz-verpleegkunde,

Hogeschool Inholland,

Amsterdam

FILIP EFTIMOV

neuroloog, Amsterdam UMC, locatie AMC

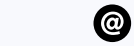

CORRESPONDENTIE ANGELA LANGERAK A.G.LANGERAK@ AMSTERDAMUMC.NL

\title{
Zelfmetingen bij patiënten met myasthenia gravis
}

De auteurs ontwikkelden een zelfmeting voor mensen met myasthenia gravis in de thuissituatie. Het doel: het zelfmanagement van patiënten vergroten, waardoor zij meer zelfvertrouwen krijgen en beter kunnen inschatten wanneer ze contact met de behandelaar moeten opnemen.

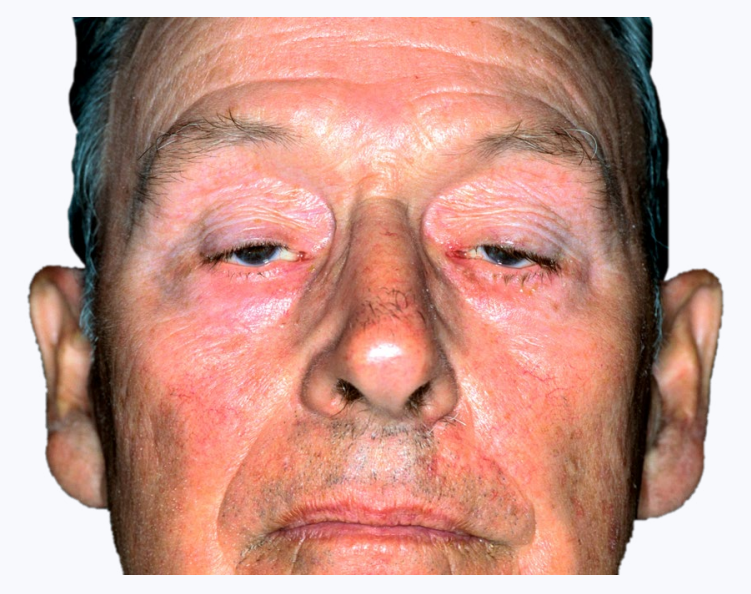

TREFWOORDEN

$\rightarrow$ Zelfmanagement

$\rightarrow$ Ziekenhuiszorg

Myasthenia gravis (MG) is een autoimmuunziekte van de neuromusculaire overgang. Hierbij ontstaat wisselende, inspannings-gebonden spierzwakte, die zich op verschillende manieren kan uiten. Symptomen zijn hangende oogleden, dubbelzien, problemen met kauwen, slikken en spreken en zwakte van de arm-, been-, nek-, rug- en ademhalingsspieren. Patiënten kunnen één of meer verschijnselen hebben. Ongeveer 15 procent heeft alleen klachten van de oogspieren (oculaire MG). De ernst van de spierzwakte verschilt per patiënt, maar kan ook bij dezelfde patiënt per moment wisselen. Meestal voelt de patiënt zich in de ochtend het best en neemt de spierzwakte in de loop van de dag toe. Het verloop van de ziekte kan grillig zijn en is moeilijk te voorspellen. Bij een myasthene crise is sprake van respiratoire insufficiëntie (ademhalingsfalen). Dit kan uitgelokt worden door onder andere een onderliggende infectie of het gebruik van sommige medicijnen. Het is dan noodzakelijk direct in te grijpen door het ondersteunen van de ademhaling en intensiveren van de behandeling.

De diagnose MG wordt gesteld op basis van de aanwezigheid van antistoffen in het bloed en/of een afwijkend elektromyografisch onderzoek. De behandeling bestaat uit sympto- 
matische en/of immunosuppressieve medicamenteuze therapie. Bij een MG-crisis wordt de behandeling aangevuld met plasmaferese (uitwassen antistoffen) of intraveneuze immunoglobuline (binding antistoffen). Met behandeling is de prognose goed. ${ }^{1-2}$ MG heeft een wereldwijde prevalentie van 40-180 per miljoen en een incidentie van 4-12 per miljoen. MG kan op elke leeftijd optreden. ${ }^{2}$

Het neuromusculair centrum van Amsterdam UMC - locatie AMC is een tertiair centrum waarnaar patiënten uit verschillende ziekenhuizen worden verwezen voor diagnostiek en behandeling van MG. In Amsterdam UMC zijn er binnen de poliklinische zorg voor patiënten met MG elke twee tot drie maanden vaste controlemomenten die gebaseerd zijn op een gemiddelde patiënt. Patiënten moeten bij toename van klachten contact opnemen met de behandelaar: een verpleegkundig specialist (VS) of neuroloog. In de praktijk blijkt dat sommige patiënten en behandelaren behoefte hebben aan intensiever contact, terwijl de standaardcontroles bij stabiele ziekte door anderen als onnodig worden ervaren. Ook vinden patiënten het moeilijk in te schatten op welk moment zij contact met de behandelaar moeten opnemen; hierdoor zoeken zij mogelijk te laat of juist onnodig vaak contact. Vervolgens is het voor de behandelaar moeilijk om telefonisch een inschatting van de ziekteactiviteit te maken.

Om de poliklinische zorg voor patiënten met MG efficiënter en patiëntgerichter te maken, ontwikkelden we een zelfmeting die patiënten thuis kunnen uitvoeren. Het doel hiervan is het zelfmanagement van patiënten met MG te vergroten, waardoor zij meer zelfvertrouwen krijgen en beter kunnen inschatten wanneer ze contact met de behandelaar moeten opnemen. Voor de lange termijn is het doel dat de behandelaar op afstand de respons op de behandeling of de urgentie van nieuwe klachten beter kan inschatten. Op basis daarvan kan een keuze voor de vervolgbehandeling gemaakt worden of controle in het ziekenhuis vervroegd worden.
De onderzoeksvragen waren:

- In hoeverre is de zelfmeting volledig en op de juiste wijze uitgevoerd?

- In hoeverre draagt de uitvoering van de zelfmeting bij aan het zelfmanagement van patiënten met MG?

- In hoeverre zijn patiënten tevreden over het gebruik van de zelfmeting?

\section{METHODE \\ Design}

Bij deze pilot-interventiestudie is voor het evalueren van het zelfmanagement (uitkomst) een pretest-posttestontwerp met één groep gebruikt. Hierbij werden de zelfmetingen als de interventie beschouwd. De patiënten hebben een pretest over hun zelfmanagementvaardigheden ingevuld. Vervolgens hebben zij gedurende de onderzoeksperiode drie keer de zelfmeting uitgevoerd, met een interval van twee weken. Er is voor gekozen om drie keer de zelfmeting uit te laten voeren, omdat de verwachting was dat er bij het uitvoeren sprake is van een leercurve. $\mathrm{Na}$ het uitvoeren van de zelfmetingen vulden de patiënten de posttest in over hun zelfmanagementvaardigheden. Er is een vergelijking gemaakt tussen hun zelfmanagementvaardigheden voor en na de interventie. De onderzoeksvragen over de wijze van uitvoering (uitkomst) en patiënttevredenheid (uitkomst) werden beantwoord met beschrijvend cross-sectioneel design. ${ }^{3} \mathrm{Na}$ de onderzoeksperiode heeft hiervoor eenmalig een kwantitatieve meting plaatsgevonden. De studie was onderdeel van een afstudeeronderzoek voor de masteropleiding tot VS en kentdaardoor een beperkte onderzoeksperiode.

\section{Interventie}

De zelfmeting bestaat uit twee onderdelen (zie figuur 1). Deel 1 is een scorelijst over myasthene symptomen en is gebaseerd op de MG-ADL-schaal. Dit is een Nederlandstalige scorelijst over MG-symptomen die vooral in researchverband wordt gebruikt, maar ook bruikbaar is in de klinische praktijk. ${ }^{4} \mathrm{Er}$ worden acht symptomen benoemd die de patiënt moet scoren in ernst. Hieruit komt een totaalscore (0-24), waarbij een hogere score overeenkomt met een ernstigere ziekteactiviteit. Deel 2 is een fysieke meting waarbij de patiënt, met behulp van een stopwatch, negen metingen uitvoert. Per onderdeel komt er een score uit, met een totaalscore (0-27). Een hogere score komt overeen met een ernstigere ziekteactiviteit. De fysieke meting is gebaseerd op de Quantitative Myasthenia Gravis-test (QMG). In de huidige situatie neemt de VS tijdens polibezoeken de QMG af. Deze bestaat uit uithoudingstesten waarmee de ziekte- activiteit inzichtelijk wordt gemaakt. Acht onderdelen van de QMG kan de patiënt zelfstandig uitvoeren; deze zijn daarom opgenomen in de zelfmeting. Op basis van ervaring hebben we een onderdeel gericht op de ademhaling toegevoegd. Als er problemen zijn met de ademhaling, kan dit duiden op een (dreigende) MG-crisis en moet direct actie worden ondernomen. ${ }^{1}$

Vooraf kregen patiënten mondelinge voorlichting van de VS en een instructiebrief met foto's over de uitvoering van de metingen. Tijdens de onderzoeksperiode konden zij bij vragen of problemen contact opnemen met de VS. Er is niet onderzocht of patiënten dit voldoende vonden.

\section{Onderzoekspopulatie en steekproef}

De onderzoekspopulatie bestaat uit patiënten met MG die onder behandeling zijn in Amsterdam UMC. De inclusiecriteria waren: bewezen MG (aanwezigheid van antistoffen en/of ondersteuning uit EMG-onderzoek), een leeftijd van 18 jaar of ouder en voldoende beheersing van de Nederlandse taal. De exclusiecriteria: oculaire MG en onvoldoende mogelijkheid om thuis zelfmetingen uit te voeren (bijvoorbeeld niet in het bezit zijn van een stopwatch of het ontbreken van ondersteuning door een naaste als ondersteuning gewenst is).

Bij een pilotonderzoek is het gebruikelijk tien tot 12 patiënten te includeren. ${ }^{3,5}$ Vanwege het risico op uitval is gekozen voor een gemakssteekproef met minimaal 15 patiënten. Alle benaderde patiënten gingen akkoord met deelname. 
FIGUUR 1 ZELFMETING

Deel 1: scoreliist myasthene symptomen

\begin{tabular}{|c|c|c|c|c|c|}
\hline \multicolumn{2}{|l|}{ Naam: } & \multicolumn{4}{|c|}{ Datum: } \\
\hline Items & Graad 0 & Graad 1 & Graad 2 & Graad 3 & $\begin{array}{l}\text { Score } \\
(0,1,2,3)\end{array}$ \\
\hline 1. Spreken & Normaal & $\begin{array}{l}\text { Van tijd tot tijd } \\
\text { ongearticuleerde } \\
\text { of nasale spraak }\end{array}$ & $\begin{array}{l}\text { Constant } \\
\text { ongearticuleerd of } \\
\text { nasaal, maar het } \\
\text { is te verstaan }\end{array}$ & $\begin{array}{l}\text { Spraak is } \\
\text { moeilijk te } \\
\text { verstaan }\end{array}$ & \\
\hline 2. Kauwen & Normaal & $\begin{array}{l}\text { Vermoeidheid bij } \\
\text { vast voedsel }\end{array}$ & $\begin{array}{l}\text { Vermoeidheid bij } \\
\text { zacht voedsel }\end{array}$ & Maagsonde & \\
\hline 3. Slikken & Normaal & Zelden verslikken & $\begin{array}{l}\text { Frequent } \\
\text { verslikken, dat } \\
\text { dieetwijziging } \\
\text { noodzakelijk } \\
\text { maakt }\end{array}$ & Maagsonde & \\
\hline 4. Ademen & Normaal & $\begin{array}{l}\text { Kortademig bij } \\
\text { inspanning }\end{array}$ & $\begin{array}{l}\text { Kortademig in } \\
\text { rust }\end{array}$ & $\begin{array}{l}\text { Afhankelijk } \\
\text { van } \\
\text { beademing }\end{array}$ & \\
\hline $\begin{array}{l}\text { 5. Vermogen } \\
\text { aangetast om } \\
\text { tanden te } \\
\text { poetsen of } \\
\text { haar te } \\
\text { kammen }\end{array}$ & Geen & $\begin{array}{l}\text { Extra inspanning, } \\
\text { maar ik heb geen } \\
\text { rustpauzes nodig }\end{array}$ & Rustpauzes nodig & $\begin{array}{l}\text { Ik kan een van } \\
\text { deze functies } \\
\text { niet uitvoeren }\end{array}$ & \\
\hline $\begin{array}{l}\text { 6. Vermogen } \\
\text { aangetast om } \\
\text { uit stoel op te } \\
\text { staan }\end{array}$ & Geen & $\begin{array}{l}\text { Mild, ik gebruik } \\
\text { soms de armen }\end{array}$ & $\begin{array}{l}\text { Matig, ik gebruik } \\
\text { altijd de armen }\end{array}$ & $\begin{array}{l}\text { Hevig, ik heb } \\
\text { hulp nodig }\end{array}$ & \\
\hline 7. Dubbelzien & Geen & $\begin{array}{l}\text { Komt voor, maar } \\
\text { niet dagelijks }\end{array}$ & $\begin{array}{l}\text { Dagelijks, maar } \\
\text { niet constant }\end{array}$ & Constant & \\
\hline $\begin{array}{l}\text { 8. Hangend } \\
\text { ooglid }\end{array}$ & Geen & $\begin{array}{l}\text { Komt voor, maar } \\
\text { niet dagelijks }\end{array}$ & $\begin{array}{l}\text { Dagelijks, maar } \\
\text { niet constant }\end{array}$ & Constant & \\
\hline
\end{tabular}

Totale MG-ADL-SCORE (item 1-8):
Deel 2: fysieke meting

\begin{tabular}{|c|c|c|c|c|c|}
\hline \multicolumn{3}{|l|}{ Naam: } & \multicolumn{3}{|c|}{ Tijdstip laatste mestinon: } \\
\hline \multicolumn{3}{|l|}{ Datum: } & \multicolumn{3}{|l|}{ Tijdstip uitvoering: } \\
\hline $\begin{array}{l}\text { Test } \\
\text { Cijfer }\end{array}$ & $\begin{array}{c}\text { Geen } \\
0\end{array}$ & $\begin{array}{c}\text { Mild } \\
1\end{array}$ & $\begin{array}{c}\text { Matig } \\
2\end{array}$ & $\begin{array}{c}\text { Zwaar } \\
3\end{array}$ & \begin{tabular}{|l} 
Score \\
$(0,1,2,3)+$ \\
seconden \\
\end{tabular} \\
\hline $\begin{array}{l}\text { 1. Dubbelzien bij } \\
\text { naar rechts } \\
\text { kijken, seconden }\end{array}$ & 60 & $11-59$ & $1-10$ & Spontaan & \\
\hline $\begin{array}{l}\text { 2. Halve beker } \\
\text { water drinken }\end{array}$ & Normaal & $\begin{array}{l}\text { Licht kuchen } \\
\text { of keel } \\
\text { schrapen }\end{array}$ & $\begin{array}{c}\text { Zwaar kuchten, } \\
\text { verslikken, } \\
\text { water dat uit de } \\
\text { neus loopt }\end{array}$ & $\begin{array}{l}\text { Ik kan niet } \\
\text { slikken }\end{array}$ & \\
\hline $\begin{array}{l}\text { 3. Spraak bij } \\
\text { tellen tot } 50 \\
\text { (begin van } \\
\text { verandering } \\
\text { spraak) }\end{array}$ & Geen bij 50 & $\begin{array}{c}\text { Dysartrie bij } \\
30-49\end{array}$ & $\begin{array}{c}\text { Dysartrie bij } \\
10-29\end{array}$ & $\begin{array}{c}\text { Dysartrie bij } \\
1-9\end{array}$ & \\
\hline $\begin{array}{l}\text { 4. Rechter arm } \\
\text { gestrekt }\left(90^{\circ} \text {, }\right. \\
\text { zittend), } \\
\text { seconden }\end{array}$ & 240 & $90-239$ & $10-89$ & $0-9$ & \\
\hline $\begin{array}{l}\text { 5. Linker arm } \\
\text { gestrekt ( } 90^{\circ} \text {, } \\
\text { zittend), } \\
\text { seconden }\end{array}$ & 240 & $90-239$ & $10-89$ & $0-9$ & \\
\hline $\begin{array}{l}\text { 6. Plat liggen, } \\
\text { seconden }\end{array}$ & 60 & $30-59$ & $1-29$ & 0 & \\
\hline $\begin{array}{l}\text { 7. Hoofd optillen } \\
\text { ( } 45^{\circ} \text {, in } \\
\text { rugligging), } \\
\text { seconden }\end{array}$ & 120 & $30-119$ & $1-29$ & 0 & \\
\hline $\begin{array}{l}\text { 8. Rechter been } \\
\text { gestrekt }\left(45^{\circ} \text {, in }\right. \\
\text { rugligging), } \\
\text { seconden }\end{array}$ & 100 & $31-99$ & $1-30$ & 0 & \\
\hline $\begin{array}{l}\text { 9. Linker been } \\
\text { gestrekt }\left(45^{\circ} \text {, in }\right. \\
\text { rugligging), } \\
\text { seconden }\end{array}$ & 100 & 31-99 & $1-30$ & 0 & \\
\hline & & & & score (item & 12 \\
\hline
\end{tabular}

\section{Dataverzameling}

Voor de eerste onderzoeksvraag (wijze van uitvoering) hield de VS in het patiëntendossier bij hoeveel patiënten de zelfmetingen volledig en juist hadden uitgevoerd. Zo is op een gestructureerde wijze inzichtelijk gemaakt hoe de uitvoering is verlopen.

Van patiënten die het volledige onderzoek hebben doorlopen zijn demografische en klinische kenmerken verzameld (zie tabel 1). Om te beoordelen of de ziekte gedurende de onderzoeksperiode stabiel was, is aan het eind aan patiënten gevraagd te beoordelen of de ziekteactiviteit op dat moment gelijk was aan het moment waarop zij begonnen met zelfmetingen.

Voor het meten van het zelfmanagement is het Patiënt Activatie Meetinstrument (PAM-13NL) gebruikt. Dit is een gevalideerd meetinstrument. Het maakt inzichtelijk of patiënten met een chronische ziekte over de juiste kennis en vaardigheden beschikken voor zelfmanagement en of ze vertrouwen hebben om deze toe te passen in de omgang met de ziekte. ${ }^{6}$ De PAM-13NL bestaat uit 13 stellingen, waarbij de patiënt op een vijfpunt-Likertschaal aangeeft in hoeverre hij het eens is met de stelling. Via de somscore kan de patiënt ingedeeld worden in vier niveaus van activatie: van de passieve (level 1) tot actieve patiënt (level 4). ${ }^{7}$ Voor het berekenen van de somscore van de PAM-13NL is een formule gebruikt waarmee een $\mathrm{Ne}$ derlandse huisartsencoöperatie werkt. De formule leidt tot een somscore (1352) op basis waarvan de patiënt ingedeeld wordt in één van de vier niveaus. ${ }^{8}$ Het algoritme van de ontwikkelaar van de PAM-13, Insignia Health, was niet beschikbaar voor dit onderzoek.

De patiënttevredenheid is uitgewerkt in een vijfpunt-Likertschaal bestaande uit negen stellingen. Om de betrouwbaarheid van de vragenlijst te vergroten is deze door drie personen beoordeeld. De stellingen zijn zowel positief als negatief geformuleerd; daardoor moet de patiënt de stellingen zorgvuldig lezen. ${ }^{3}$ Per item wordt een score (1-5) verkregen. Hoe hoger de somscore, hoe groter de patiënttevredenheid.

\section{Data-analyse}

De data over de wijze van uitvoering zijn beschrijvend weergegeven. De resultaten van voor en na interventie met de PAM-13NL (zelfmanagement) zijn uitgesplitst in een PAM-score en PAM-niveau. Voor de PAM-score is een 
TABEL 1 DEMOGRAFISCHE EN KLINISCHE KENMERKEN ( $\mathrm{N}=16)$

\begin{tabular}{l|c}
\hline Leeftijd in jaren; gemiddelde (range; SD) & $58(24-82 ; 17)$ \\
\hline Geslacht; $n(\%)$ & \\
- Man & $6(37,5)$ \\
- Vrouw & $10(62,5)$ \\
\hline Antistoffen; $n(\%)$ & \\
- AChR+ ${ }^{a}$ & $13(81,3)$ \\
- Seronegatief & $3(18,8)$ \\
\hline Stabiele ziekte; $n(\%)^{c}$ & \\
- Mee oneens & $3(18,8)$ \\
- Niet mee oneens en niet mee eens & $1(6,3)$ \\
- Mee eens & $3(18,8)$ \\
- Zeer mee eens & $9(56,3)$ \\
\hline
\end{tabular}

'Antistoffen tegen acetylcholinereceptoren

${ }^{\mathrm{b}} \mathrm{Geen}$ antistoffen aantoonbaar

'De niet gekozen antwoordmogelijkheden zijn niet weergegeven

mediaan met een eerste en derde kwartiel (Q1 en Q3) berekend. Vervolgens zijn de uitkomsten van de pre- en posttest getoetst met de Wilcoxon-toets. De alpha is 0.05 .

Voor de uitkomst 'patiënttevredenheid' is over de somscore de mediaan met een eerste en derde kwartiel (Q1 en Q3) berekend. De uitkomsten van de vragen zijn ook beschrijvend weergegeven.

\section{RESULTATEN}

De zelfmetingen zijn door 16 (84 procent) van de 19 geïncludeerde patiënten volledig en juist uitgevoerd. Drie patiënten zijn uitgevallen vanwege een ziekteperiode anders dan MG. De kenmerken van de 16 patiënten staan in tabel 1 .

\section{Zelfmanagement}

De PAM-13NL geeft met een PAMscore en bijpassend PAM-niveau inzicht in de mate van zelfmanagement (zie tabel 2). Voor de PAM-score is het verschil tussen de pretest $($ mediaan $=42)$ en de posttest (mediaan $=43,5)$ niet significant. Bij de posttest is het aantal patiënten met het hoogste PAM-niveau met twee gestegen en er is geen patiënt meer in het laagste PAM-niveau. Het PAMniveau verschilt niet significant tussen de pre- en posttest.

\section{Patiënttevredenheid}

De mediaan van de somscore (5-45) over patiënttevredenheid is 36 . Alle patiënten vinden de zelfmeting

TABEL 2 RESULTATEN PRE- EN POSTTEST MIDDELS PAM-13NL ( $N=16$ )

\begin{tabular}{l|l|l|l}
\hline Uitkomst & Pretest & Posttest & P-waarde $^{\mathbf{a}}$ \\
\hline PAM-score (13-52); mediaan (Q1; Q3) & $42(39 ; 46)$ & $43,5(39,5 ; 48,8)$ & 0.176 \\
\hline PAM-niveau; $n$ (\%) & & & 0.366 \\
- PAM 1 & $1(6,3)$ & $0(0)$ & \\
- PAM 2 & $2(12,5)$ & $2(12,5)$ & \\
- PAM 3 & $8(50)$ & $7(43,8)$ & \\
- PAM 4 & $5(31,3)$ & $7(43,8)$ & \\
\hline
\end{tabular}

aWilcoxon toets

gebruiksvriendelijk. Ook geven zij aan dat de zelfmeting geen belasting is. Acht patiënten (50 procent) vinden dat hun kennis over MG is toegenomen door de zelfmeting en dat zij beter weten wanneer zij contact moeten opnemen met de behandelaar. Van de patiënten vinden er 12 (75 procent) dat het toepassen van de zelfmeting de zorgverlening verbetert. Verder voelen 14 ( 87,5 procent) zich er veilig bij om de frequentie van de ziekenhuisbezoeken te laten afhangen van de uitkomst van de zelfmeting. Alle patiënten zijn gemotiveerd om de zelfmeting te blijven gebruiken.

\section{DISCUSSIE}

We hebben een zelfmeting ontwikkeld en geïmplementeerd om de poliklinische zorg voor patiënten met MG efficienter en patiëntgerichter te maken. Patiënten zijn tevreden over het gebruik, ze beoordeelden de zelfmeting over het geheel als neutraal tot positief. Er is geen significant verschil gevonden ten aanzien van het zelfmanagement van patiënten. Deze pilotstudie levert belangrijke informatie over de toepasbaarheid van een zelfmeting voor patiënten met MG.

Eerdere studies naar zorg op afstand bij patiënten met $M G$ werden niet gevonden. Patiënten met amyotrofische laterale sclerose, een andere neuromusculaire aandoening, zijn tevreden over een app waarin ze bijhouden hoe het met ze gaat. ${ }^{9}$ Deze tevredenheid komt overeen met de resultaten van dit onderzoek. Een vergelijking met andere onderzoeken met de PAM-13-vragenlijst was niet mogelijk vanwege het ontbreken van het algoritme.

Waarom is er geen significant verschil gevonden voor zelfmanagement? Dit kan verklaard worden door de beperkte onderzoekspopulatie en de relatief korte onderzoeksperiode, ongeveer tien weken, met een wisselend interval tussen de interventie en de afname van de uitkomst. Het is onwaarschijnlijk dat in korte tijd gedragsverandering plaatsvindt. Verder scoorden bij baseline 13 patiënten al een hoge mate van zelfmanagement. Het was de verwachting dat voor hen een verbetering binnen de beperkte tijd moeilijk zou zijn. Bovendien heeft de variabiliteit in ziekteactiviteit mogelijk de PAM-score van enkele patiënten beïnvloed. Drie patiënten gaven aan dat de ziekte gedurende de onderzoeksperiode niet stabiel was en één patiënt was neutraal ten aanzien van deze stelling. Drie van deze vier patiënten lieten bij de posttest een daling van de PAM-score zien en bij de vierde patiënt bleef de PAM-score gelijk. Bij de zelfmeting zijn geen afkapwaarden afgesproken voor wanneer patiënten contact moeten opnemen met de behandelaar. Bij het beoordelen van de zelfmetingen gaat het namelijk om trendbewaking. Mogelijk hebben het ontbreken van afkapwaarden en afspraken over contact opnemen geleid tot onduidelijkheid bij patiënten. En mogelijk had dit invloed op de mate van zelfmanagement en patiënttevredenheid. Patiënten met een lage posttestPAM-score scoorden zowel laag als hoog op patiënttevredenheid. Ook patiënten met een hoge posttest-PAMscore scoorden wisselend op de uitkomst patiënttevredenheid. De PAM-score lijkt daardoor niet van invloed te zijn op de patiënttevredenheid. Het niet actief begeleiden van patiënten toen ze de zelfmeting moesten uitvoeren en het feit dat de uitkomsten 
niet direct met de behandelaar konden worden gedeeld, kunnen de motivatie van de patiënt en daarmee de patiënttevredenheid negatief beïnvloed hebben. Een sterk punt van dit onderzoek is dat voldoende patiënten deelnamen voor een pilotstudie en dat alle benaderde patiënten akkoord gingen met deelname. De patiënten die zijn uitgevallen kregen gedurende de onderzoeksperiode een bijkomend gezondheidsprobleem. Ondanks uitleg van de VS dat juist op zulke momenten de zelfmetingen behulpzaam kunnen zijn, zagen zij af van deelname. Dit kan gezorgd hebben voor selectiebias, omdat deze patiënten tijdens een bijkomende ziekteperiode mogelijk ook een instabiele MG kregen en/of zij het uitvoeren van de zelfmetingen te belastend vonden. De validiteit van dit onderzoek is beperkt vanwege een relatief kleine onderzoekspopulatie en korte onderzoeksperiode. De uitkomsten zijn wel praktisch relevant voor de poliklinische zorg voor patiënten met MG in het
Amsterdam UMC. Er is geen significant verschil aangetoond in zelfmanagement, maar patiënten blijken tevreden te zijn en ervaren de zelfmetingen niet als een belasting. Het uitvoeren van zelfmetingen lijkt ook geen nadelig effect op patiënten te hebben.

De conclusie: de zelfmeting is een waardevolle aanvulling op de huidige poliklinische zorg in het Amsterdam UMC. De frequentie van het uitvoeren van de zelfmeting verschilt per patiënt. Bij stabiele ziekte is de frequentie lager dan wanneer de ziekte actief is en er regelmatig aanpassingen in de behandeling worden gedaan. Op deze manier wordt zorg op maat geboden. Tijdens de COVID-19-crisis is de zelfmeting een praktische aanvulling op videoconsulten. Om meer inzicht te krijgen in het effect van zelfmetingen op het zelfmanagement, is onderzoek nodig met een grotere populatie en over een langere periode. Daarnaast wordt onderzoek geadviseerd naar het op afstand inschatten van de ziekteactiviteit door behan- delaren, waarbij het waarborgen van de veiligheid bij deze kwetsbare groep een absolute vereiste blijft.

\section{REFERENTIES}

1. Kuks JB. Neuromusculaire overgangsstoornissen. Nervus. 2018;2:30-38.

2. Gilhus NE \& Verschuuren JJ. Myasthenia gravis: subgroup classification and therapeutic strategies. The Lancet Neurology. 2015;14:1023-1036.

3. Nieswiadomy RM, Ter Maten A \& Hoogerduijn

J. Verpleegkundige onderzoeksmethoden. Derde druk. Amsterdam: Pearson Benelux. 2013.

4. Muppidi S. The Myasthenia Gravis - Specific Activities of Daily Living Profile. Myasthenia Gravis and Related Disorders I. 2012;1274:114-119.

5. Julious SA. Sample size of 12 per group rule of thumb for a pilot study. Pharmaceutical Statistics. 2005:4:287-291.

6. Hendriks M, Plass AM, Heijmans M, e.a.

Minder zelfmanagementvaardigheden, dus meer zorggebruik? Nivel. www.nivel.nl.

7. Zelfzorg Ondersteund Instrumentenkiezer. PAM (Patiënt Activation Measure). www.zelfzorgondersteund.

8. Dokterscoop. Patiënt Activatie Meetinstrument, introductie voor de zorgverlener. www.dokterscoop.nl. 9. ALS Centrum Nederland. ALS-patiënten tevreden over zorg op maat door eHealth. www.als-centrum.nl.

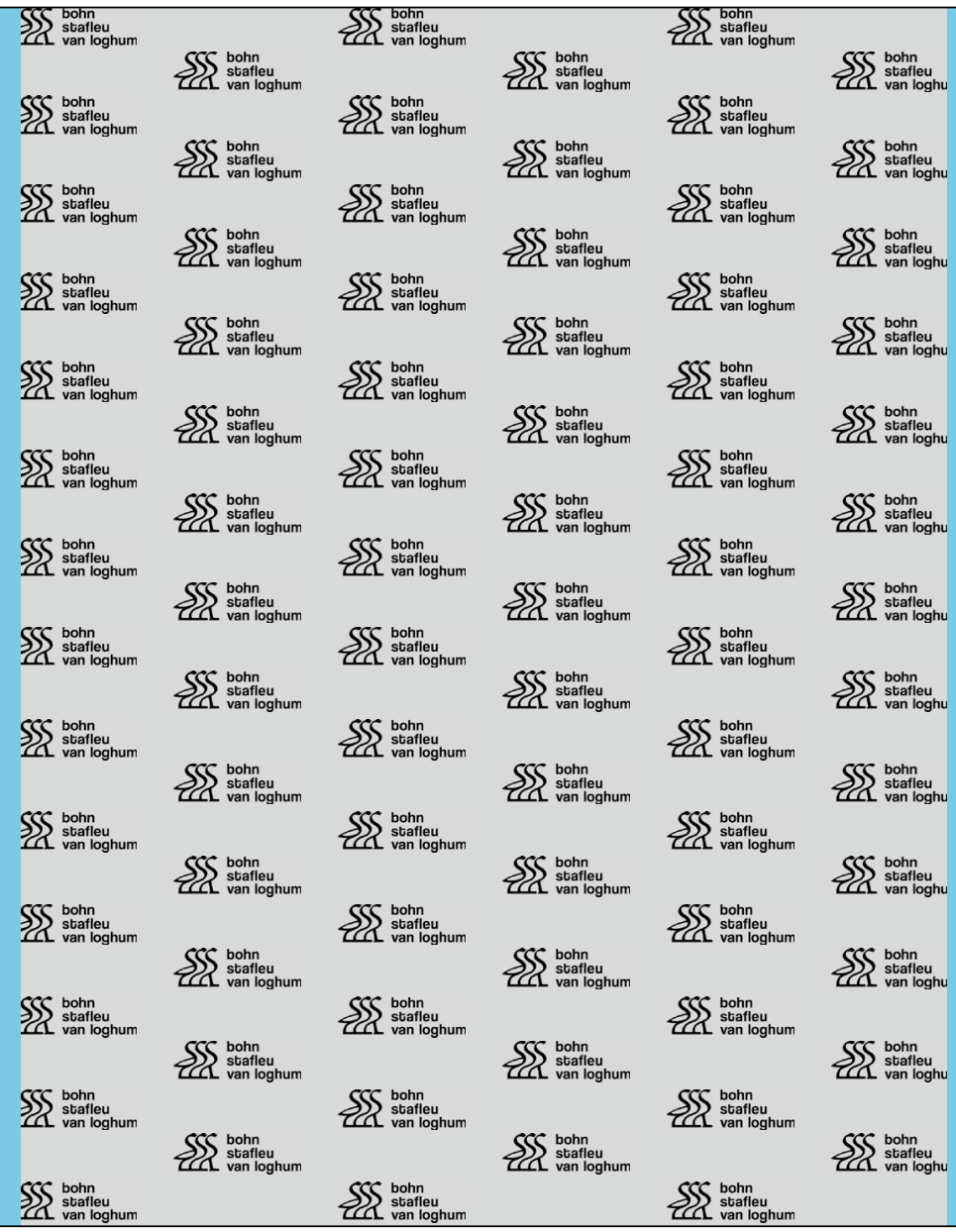

